\title{
PENGARUH KOMPENSASI, KEPUASAN KERJA DAN STRES KERJA TERHADAP KINERJA KARYAWAN PT. MEDITECH INDONESIA
}

\author{
Riski Andriyani ${ }^{1}$, M. Tony Nawawi ${ }^{2}$ \\ ${ }^{1}$ Program Studi Manajemen, Fakultas Ekonomi dan Bisnis, Universitas Tarumanagara \\ Email: riski.115170250@stu.untar.ac.id \\ ${ }^{2}$ Program Studi Manajemen, Fakultas Ekonomi dan Bisnis, Universitas Tarumanagara* \\ Email:tonyn@fe.untar.ac.id \\ *Penulis Korespondensi
}

Masuk : 02-08-2021, revisi: 15-08-2021, diterima untuk diterbitkan : 30-08-2021

\begin{abstract}
ABSTRAK
Penelitian ini dilakukan dengan tujuan untuk mengetahui pengaruh kompensasi terhadap kinerja karyawan, pengaruh kepuasan kerja terhadap kinerja karyawan dan pengaruh stres kerja terhadap kinerja karyawan pada PT. Meditech Indonesia. Subjek yang terdapat dalam penelitian ini adalah sebanyak 34 responden yaitu merupakan para karyawan PT. Meditech Indonesia. Penelitian ini menggunakan metode pengambilan sampel dengan adalah sampel jenuh. Analisis data yang digunakan dalam penelitian ini adalah Partial Least Square (PLS) yang merupakan aplikasi SmartPLS 3.0. Hasil temuan penelitian ini menunjukkan bahwa kompensasi memiliki pengaruh terhadap kinerja karyawan, kepuasan kerja memiliki pengaruh terhadap kinerja karyawan, dan stres kerja tidak memiliki pengaruh terhadap kinerja karyawan.
\end{abstract}

Kata Kunci: Kompensasi, kepuasan kerja, stres kerja, kinerja karyawan

\section{ABSTRACT}

This research was conducted with the aim of knowing the effect of compensation on employee performance, the effect of job satisfaction on employee performance and the effect of job stress on employee performance at PT. Meditech Indonesia. The subjects contained in this study were 34 respondents, namely employees of PT. Meditech Indonesia. This study uses a sampling method with a saturated sample. Analysis of the data used in this study is Partial Least Square (PLS) which is a SmartPLS 3.0 application. The findings of this study indicate that compensation has an effect on employee performance, job satisfaction has an influence on employee performance, and job stress has no effect on employee performance.

Keywords: Compensation, job satisfaction, job stress, employee performance

\section{PENDAHULUAN}

\section{Latar Belakang}

Peningkatan perekonomian Indonesia tidak terlepas dari kinerja perusahaan. Kinerja suatu perusahaan akan meningkat apabila terdapat kerjasama dan hubungan yang baik antara pimpinan dengan karyawannya. Kinerja karyawan yang meningkat akan meningkatkan kinerja perusahaan. Dalam sebuah perusahaan, aspek Sumber Daya Manusia (SDM) memegang peranan penting. Sumber daya manusia merupakan faktor yang sangat menentukan kemajuan sebuah organisasi. Bahkan bisa dikatakan sumber daya manusia merupakan unsur terpenting disamping unsur lain, seperti modal, bahan baku, dan mesin. Tidak ada satu perusahaan yang dapat tumbuh dan berkembang tanpa unsur manusia dengan kemampuan manajerial dan moralitas kerja yang memadai. Hal ini sesuai dengan yang dikemukakan oleh Hasibuan (2006:12), yang menyatakan bahwa karyawan adalah kelayakan utama suatu perusahaan, karena tanpa keikutsertaan mereka, aktivitas perusahaan tidak akan terjadi. 
Berdasarkan penelitian Anton dan Euis (2014) mengungkapkan kompensasi memberikan pengaruh yang signifikan terhadap kinerja pegawai. Hal ini menandakan pengaruh antara besaran kompensasi yang diberikan dengan kinerja pegawai. Adapun hasil penelitian yang dilakukan oleh Ismi, Tetra dan Siti (2016) bahwa stres kerja berpengaruh secara positif dan signifikan terhadap kinerja karyawan karena tingkat stres yang dialami karyawan masih dalam tingkatan wajar dan dapat di kontrol pada masing-masing individu dalam hal ini responden tidak terjadi stres yang berlebihan dalam pekerjaan yang dibebankan pihak PT. Midi Utama Indonesia Tbk Cabang Samarinda. Tujuan dari penelitian ini adalah untuk mengetahui pengaruh kompensasi, kepuasan kerja dan stres kerja terhadap kinerja karyawan PT. Meditech Indonesia.

\section{Kajian teori}

Kompensasi merupakan upah yang diterima oleh seorang individu sebagai imbalan dari pekerjaan yang mereka lakukan, yang secara umum merupakan sumber financial security mereka. Milkovich (2014). Teori tersebut menggambarkan bahwa kompensasi merupakan sumber rasa aman terhadap keuangan soerang pegawai. Bila seorang pegawai merasa aman terhadap keuangannya, maka mereka akan lebih merasa nyaman dalam bekerja dan dapat bekerja dengan baik serta memberikan kemampuan terbaik mereka dalam bekerja.

Robbins dan Coulter (2011) mendefiniskan job satisfaction sebagai sikap umum seseorang terhadap pekerjaannya, dimana seseorang dengan kepuasan kerja yang tinggi mempunyai sikap positif terhadap pekerjaannya dan sebaliknya. Berdasarkan teori tersebut dapat diartikan bila pegawai yang memiliki kepuasan kerja yang tinggi, maka akan bekerja dengan lebih baik dan sebaliknya, bila pegawai yang memiliki kepuasan kerja yang rendah akan memiliki performa yang kurang baik.

Menurut Greenberg and Baron (2008), stres merupakan model yang terdiri dari keadaan emosional dan psikologis. Stres kerja merupakan konsekuensi dari ketimpangan antara harapan seseorang dengan situasi nyata di tempat kerja.

Kinerja kerja adalah hasil dari usaha seseorang yang dicapai dengan adanya kemampuan dan perbuatan dalam situasi tertentu. Byars (1984) dikutip (Kurniawan, 2012). Kinerja karyawan haruslah selalu di perhatikan, kinerja karyawan akan meningkat apabila karyawan merasa nyaman pada saat bekerja, dapat terpenuhinya kebutuhannya, dan tigkat stres yang rendah didalam tempat kerja.

Dalam penelitian ini, peneliti ingin mengetahui apakah adanya pengaruh antara kompensasi, kepuasan kerja dan stres kerja terhadap kinerja karyawan. Dalam penelitian yang dilakukan oleh Jonathan dan Ronnie (2020) menyatakan adanya pengaruh signifikan kompensasi terhadap kinerja karyawan. Kemudian penelitian yang dilakukan oleh Rahadian dan Tony Nawawi, (2020) menyatakan adanya pengaruh signifikan job satisfaction dengan employee performance. Adapun penelitian yang dilakukan oleh Ismi, Tetra dan Siti, (2016) menyatakan pengaruh secara positif dan signifikan antara stres kerja terhadap kinerja karyawan.

Kerangka pemikiran dalam penelitian ini ditunjukkan pada Gambar 1. 


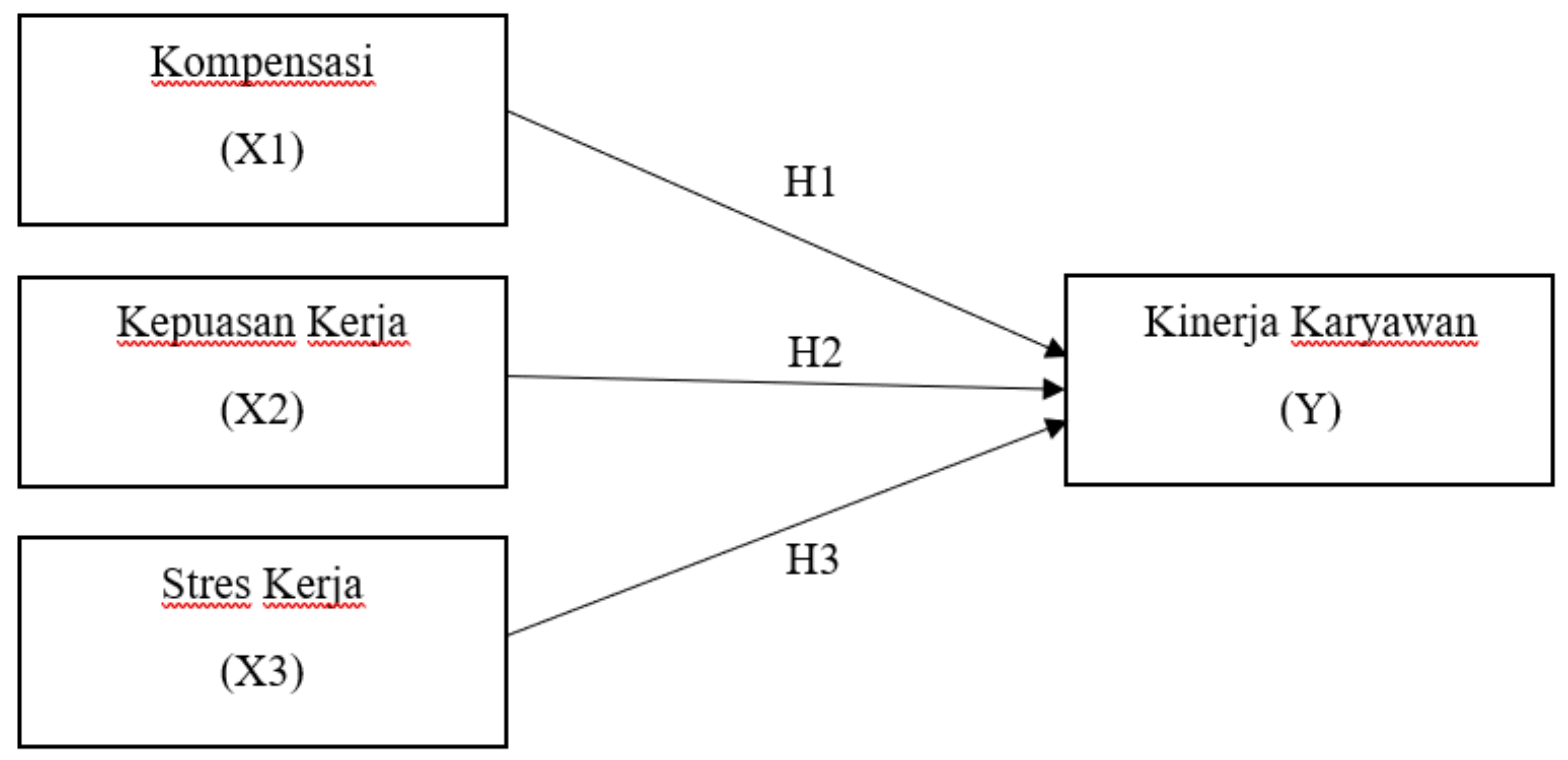

Gambar 1. Kerangka pemikiran

\section{Hipotesis}

Berdasarkan kerangka pemikiran, hipotesis pada penelitian ini dirumuskan sebagai berikut:

H1 : Kompensasi berpengaruh signifikan terhadap kinerja karyawan

H2 : Kepuasan kerja berengaruh signifikan terhadap kinerja karyawan

H3 : Stres kerja berpengaruh signifikan terhadap kinerja karyawan

\section{METODE PENELITIAN}

\section{Desain penelitian}

Menurut Sekaran \& Bougie (2016: 45) Secara umum, desain penelitian merupakan suatu rencana untuk melakukan pengumpulan, pengukuran, dan analisis data atas pertanyaan pada penelitian menyatakan bahwa desain penelitian di bagi menjadi 3, yaitu desain penelitian eksploratif, deskriptif, dan kausal. Dalam penelitian ini menggunakan desain kausal, yaitu suatu desain penelitian yang disusun untuk meneliti kemungkinan adanya hubungan sebab-akibat antar variabel (Sanusi, 2011).

\section{Populasi, Teknik Pemilihan Sample dan Ukuran Sample}

Dalam penelitian ini, populasi yang diambil adalah karyawan PT. Meditech Indonesia yang berjumlah 34 karyawan. Teknik pengambilan sampel yang digunakan dalam penelitian ini yaitu sampel jenuh, yaitu teknik penentuan sampel bila semua anggota populasi dijadikan sampel (Sugiyono, 2014:118).

Dalam penelitian ini menggunakan pengujian data dengan pendekatan Partial Least Square (PLS) dengan program SmartPLS versi 3. Uji statistik yang terdiri dari uji validitas konvergen, uji validitas diskriminan, uji realibilitas. Kemudian untuk uji analisis menggunakan pengujian uji koefisien determinasi (R-square), uji Q-square, uji multikolineritas, uji hipotesis dan uji signifikansi

\section{HASIL DAN PEMBAHASAN}

Validitas konvergen merupakan menilai sejauh mana dua ukuran kosntruksi yang sama saling terkait. Nilai dalam uji validitas konvergen dari model pengukuran (outer model) mencerminkan reliabilitas semua indikator dalam model. Uji validitas konvergen yang baik jika nilai indikator 
model pengukuran dari masing-masing konstruk dalam model yang lebih besar dari $>0,50$ maka dapat dikatakan valid (Hair et al., 2010).

Tabel 1. Uji Validitas

Sumber: Olah data SmartPLS 3.0

\begin{tabular}{|c|c|c|c|c|c|}
\hline & Kompensasi & Kepuasan Kerja & Stres Kerja & Kinerja Karyawan & Keterangan \\
\hline K1 & 0.757 & & & & Valid \\
\hline K2 & 0.801 & & & & Valid \\
\hline K3 & 0.849 & & & & Valid \\
\hline K4 & 0.731 & & & & Valid \\
\hline K5 & 0.763 & & & & Valid \\
\hline KK1 & & 0.802 & & & Valid \\
\hline KK2 & & 0.790 & & & Valid \\
\hline KK3 & & 0.747 & & & Valid \\
\hline KK4 & & 0.729 & & & Valid \\
\hline KK5 & & 0.817 & & & Valid \\
\hline SK1 & & & 0.776 & & Valid \\
\hline SK2 & & & 0.744 & & Valid \\
\hline SK3 & & & 0.794 & & Valid \\
\hline SK4 & & & 0.744 & & Valid \\
\hline SK5 & & & 0.729 & & Valid \\
\hline KI1 & & & & 0.756 & Valid \\
\hline $\mathrm{KI} 2$ & & & & 0.803 & Valid \\
\hline KI3 & & & & 0.785 & Valid \\
\hline KI4 & & & & 0.745 & Valid \\
\hline KI5 & & & & 0.735 & Valid \\
\hline
\end{tabular}

Tabel 2. Hasil Uji Average Variance Extracted

Sumber: Olah data SmartPLS 3.0

\begin{tabular}{|c|c|c|}
\hline Variabel & Nilai AVE & Keterangan \\
\hline Kompensasi & 0.611 & Valid \\
\hline Kepuasan Kerja & 0.605 & Valid \\
\hline Stres Kerja & 0.574 & Valid \\
\hline Kinerja Karyawan & 0.585 & valid \\
\hline
\end{tabular}

Uji validitas diskriminan adalah konsep untuk mencari tau perbedaan nilai validitas satu variabel dengan variabel lainnya. Uji validitas diskriminan dapat diukur dengan Average Variance Extracted (AVE) dari nilai korelasi antar variabel. Dari tabel 2 diatas kompensasi mempunyai nilai AVE sebesar 0.611, kepuasan kerja sebesar 0.605, stres kerja sebesar 0.574, dan kinerja karyawan sebesar 0.585. Data diatas menunjukkan keempat variabel tersebut valid, karena Nilai pengukuran AVE yang direkomendasikan adalah lebih dari 0.50 .

Tabel 3. Hasil Analisis Cronbach's Alpha

Sumber: Olah data SmartPLS3.0

\begin{tabular}{|c|c|c|}
\hline Variabel & Nilai Cronbach's Alpha & Keterangan \\
\hline Kompensasi & 0.842 & Reliabel \\
\hline Kepuasan Kerja & 0.837 & Reliabel \\
\hline Stres Kerja & 0.815 & Reliabel \\
\hline Kinerja Karyawan & 0.823 & Reliabel \\
\hline
\end{tabular}

Pengujian Reliabilitas ini bertujuan untuk mengetahui seberapa tepat dan konsisten variabel yang digunakan. Pengukuran yang digunakan yaitu dengan melihat nilai Cronbach's Alpha atau Composite Reliability, dimana nilai standar reabilitas yang dapat diterima adalah > 0.7. 
Berdasarkan Tabel 3 di atas menunjukkan bahwa variabel kompensasi, kepuasan kerja, stres kerja, dan kinerja karyawan memiliki nilai Cronbach's Alpha masing-masing sebesar 0.842, 0.837, 0.815, 0.823. Maka nilai Cronbach's Alpha dari masing-masing variabel tersebut lebih besar dari 0,7 dan dikatakan reliabel.

Tabel 4. Hasil Keofisien Determinan

Sumber: Olah data SmartPLS 3.0

\begin{tabular}{|c|c|}
\hline Variabel & $\mathbf{R}^{\mathbf{2}}$ \\
\hline Kinerja Karyawan & 0,676 \\
\hline
\end{tabular}

Merujuk pada Tabel 4, menunjukkan bahwa nilai $\mathrm{R}^{2}$ dari variabel kinerja karyawan sebesar 0.676 yang berarti adanya perubahan pada variabel kompensasi, variabel kepuasan kerja dan variabel stres kerja maka akan terjadi perubahan pada variabel kinerja karyawan sebesar 67,6\%, sisanya sebesar $32,4 \%$ dapat dipengaruhi oleh variabel lain yang tidak ada pada penelitian ini.

Tabel 5. Hasil $Q$-Square

Sumber: Olah data SmartPLS 3.0

\begin{tabular}{|c|c|}
\hline Variabel & $\boldsymbol{Q}$-square \\
\hline Kinerja Karyawan & 0,348 \\
\hline
\end{tabular}

Berdasarkan Tabel 5 didapatkan pengolahan data SmartPLS. Q-square menunjukan hasil sebesar 0.348 atau sebesar $34.8 \%$. Berdasarkan hasil tersebut dapat disimpulkan bahwa nilai $Q$-square pada penelitian ini termaksuk golongan prediksi "relevansi yang sedang".

Tabel 6. Hasil Uji Path Coefficient

Sumber: Olah data SmartPLS3.0

\begin{tabular}{|c|c|}
\hline Variabel & Path Coefficient \\
\hline Kompensasi $\rightarrow$ Kinerja Karyawan & 0.480 \\
\hline Kepuasan Kerja $\rightarrow$ Kinerja Karyawan & 0.405 \\
\hline Stres Kerja $\rightarrow$ Kinerja Karyawan & 0.129 \\
\hline
\end{tabular}

Berdasarkan Tabel 6 dapat dilihat hasil uji path coefficient untuk kinerja karyawan, dari hasil uji tersebut terlihat nilai yang paling kuat adalah variabel kompensasi sebesar 0.480 dan stres kerja adalah variabel terlemah dengan nilai sebesar 0.129 .

Tabel 7. Significance Test

Sumber: Olah data SmartPLS 3.0

\begin{tabular}{|c|c|c|c|}
\hline Variabel & t-statistics & $p$-value & Hasil \\
\hline Kompensasi $\rightarrow$ Kinerja Karyawan & 3.920 & 0.000 & Tidak Ditolak \\
\hline Kepuasan Kerja $\rightarrow$ Kinerja Karyawan & 3.148 & 0.002 & Tidak Ditolak \\
\hline Stres Kerja $\rightarrow$ Kinerja Karyawan & 1.236 & 0.217 & Ditolak \\
\hline
\end{tabular}

Berdasarkan Tabel 7 dapat dilihat variabel yang memiliki pengaruh positif dan signifikan terhadap kinerja karyawan adalah kompensasi dan kepuasan kerja. Sedangkan variabel stres kerja tidak memiliki pengaruh tidak positif dan tidak signifikan terhadap kinerja karyawan.

Hasil uji hipotesis, jika t-statistik lebih kecil dari 1.96 dan p-value lebih besar dari 0.05 maka dapat disimpulkan hasil pengaruh tersebut signifikan. Dapat disimpulkan hasil pengujian hipotesisnya adalah: 


\section{H1: Kompensasi berpengaruh signifikan terhadap kinerja karyawan.}

Hasil pengujian dari variabel kompensasi terhadap kinerja karyawan menunjukkan nilai t-statisik sebesar 3.920 dan nilai p-value sebesar 0.000, jadi H1 tidak ditolak, maka dapat disimpulkan bahwa kompensasi memiliki pengaruh terhadap kinerja karyawan secara positif dan signifikan.

\section{H2: Kepuasan kerja berengaruh signifikan terhadap kinerja karyawan.}

Hasil pengujian dari variabel kepuasan kerja terhadap kinerja karyawan menunjukkan nilai tstatisik sebesar 3.148 dan nilai p-value sebesar 0.002, jadi $\mathrm{H} 2$ tidak ditolak, maka dapat disimpulkan bahwa kepuasan kerja memiliki pengaruh terhadap kinerja karyawan secara positif dan signifikan.

\section{H3: Stres kerja tidak berpengaruh signifikan terhadap kinerja karyawan.}

Hasil pengujian dari variabel stres kerja terhadap kinerja karyawan menunjukkan nilai t-statisik sebesar 1.236 dan nilai p-value sebesar 0.217, jadi H3 ditolak, maka dapat disimpulkan bahwa stres kerja tidak memiliki pengaruh terhadap kinerja karyawan secara positif dan signifikan.

\section{Diskusi}

Dalam penelitian ini didapatkan hasil pengujian yang dapat disimpulkan kompensasi memiliki pengaruh positif dan signifikan terhadap kinerja karyawan. Penelitian ini didukung oleh hasil penelitian yang dilakukan Jefta \& M. Tony (2020), yang menyatakan kompensasi berpengaruh terhadap kinerja karyawan. Ia berpendapat bahwa untuk perusahaan dapat meningkatkan pemberian bonus kepada karyawan apabila hasil pekerjaan melebihi target yang telah ditetapkan. Pimpinan bisa memberikan apresiasi yang lebih atas prestasi kerja karyawan dalam bentuk bonus berupa uang ataupun fasilitas. Begitu juga dengan penelitian yang dilakukan oleh Jonathan \& Ronnie (2020), yang menyatakan kompensasi memiliki pengaruh signifikan terhadap kinerja karyawan.

Berdasarkan penelitian yang telah dilakukan, dapat disimpulkan bahwa kepuasan kerja berpengaruh positif dan signifikan terhadap kinerja karyawan. Sejalan dengan penelitian yang dilakukan oleh Rahadian \& M. Tony (2020), yang menyatakan pengaruh positif dan signifikan job satisfaction dengan employee performance. Ia berpendapat kinerja karyawan juga dipengaruhi oleh seberapa puas mereka dengan kondisi mereka di dalam perusahaan, baik melalui pemberian upah dan gaji yang tepat, sampai pada pekerjaan mereka itu sendiri. Begitu juga dengan penelitian yang dilakukakan oleh Jessica \& Anas (2018), yang menyatakan faktor kepuasan kerja berpengaruh secara parsial terhadap kinerja karyawan. Pengaruh dari faktor kepuasan kerja dalam penelitian ini sangat signifikan setelah motivasi kerja.

Berdasarkan penelitian yang telah dilakukan, dapat disimpulakan bahawa stres kerja tidak berpengaruh dan tidak signifikan terhadap kinerja karyawan. Hasil ini berbanding terbalik dengan Ismi, Tetra \& Siti (2016) yang menyatakan terdapat pengaruh secara positif dan signifikan antara stres kerja terhadap kinerja karyawan. Serupa dengan Winner \& Sri (2018) yang menyatakan bahwa stres kerja memiliki hasil positif dan signikan terhadap kinerja karyawan. Hal tersebut dapat dikatakan bahwa karyawan pada PT. Meditech Indonesia dapat terjadi karena perlakuan baik serta beban kerja yang diberikan oleh perusahaan masih mampu diterima oleh karyawan.

\section{KESIMPULAN DAN SARAN}

Berdasarkan hasil data analisis yang telah dilakukan pada penelitian ini, maka peneliti memperoleh kesimpulan kompensasi berpengaruh signifikan terhadap kinerja karyawan, 
Kepuasan kerja berpengaruh signifikan terhadap kinerja karyawan., Stres kerja tidak berpengaruh signifikan terhadap kinerja karyawan. Variabel yang memiliki pengaruh paling besar adalah kompensasi, maka kompensasi perlu diperhatikan oleh atasan PT. Meditech Indonesia.

\section{SARAN}

1. Berikut adalah beberapa saran untuk penelitian selanjutnya:

a. Penelitian selanjutnya dapat menambahkan atau menggunakan variabel lain, seperti budaya organisasi, motivasi, komitmen organisasi dan lingkungan kerja. Sehingga dapat memberikan informasi yang lebih baik dalam meningkatkan kinerja karyawan.

b. Untuk penelitian selanjutnya dapat memperbanyak jumah populasi dan sampel yang digunakan agar dapat memperoleh tingkat kinerja karyawan yang lebih beragam.

c. Diharapkan peneliti selanjutnya dapat meningkatkan indikator variabel kinerja karyawan dengan penambahan indikator lain, seperti efisiensi perkerja, kehadiran, kualitas dan efektivitas.

2. Berikut adalah saran untuk perusahaan:

a. Uang makan yang diberikan oleh perusahaan dapat di perbesar agar dapat meningkatkan pendapatan mereka.

b. Sebaiknya perusahaan lebih memperhatikan pekerjaan karyawan agar dapar sesuai dengan keahliannya.

c. Beban kerja yang diberikan perusahaan tidak begitu sesuai dengan tanggung jawab karyawan.

d. Karyawan dapat bekerja sama dengan baik, sebaiknya perusahaan lebih memanfaatkan hal tersebut untuk kemajuan perusahaan.

\section{REFERENSI}

Anton Tirta Komara \& Euis Nelliawati (2014) Pengaruh Kompensasi, Motivasi dan Kepuasan Kerja Terhadap Kinerja Pegawai Negeri Sipil (PNS) di Lingkungan rumah Sakit Umum Daerah (RSUD) Kota Bandung, STIE Pasundan Bandung

Byars, L. L. and L.W.Rue. (1984). Human Resort Management, Mc Graw Hill: New York.

Greenberg, J. \& Baron, R. A. (2008). Behaviour in organizations. Upper Saddle River, New Jersey: Pearson-Prentice hall.

Hair, Jr et.al. (2010). Multivariate Data Analysis (7th ed). United States: Pearson

Hasibuan, Malayu S.P, 2006, Manajemen Dasar, Pengertian, dan Masalah, Edisi Revisi, Bumi Aksara: Jakarta.

Ismi Rija Nur, Tetra Hidayati dan Siti Maria (2016) Pengaruh Konflik Peran, Ambiguitas Peran Dan Stres Kerja Terhadap Kinerja Karyawan. Fakultas Ekonomi dan Bisnis Universitas Mulawarman, Indonesia

Jessica Novia dan Anas Lutfi (2018) Pengaruh Faktor Kepuasan Kerja Dan Motivasi Kerja Terhadap Kinerja Karyawan Pada Divisi Finance Di PT. XYZ Cabang Head Office. Program Studi Magister Manajemen Universitas Tarumanagara

Jonathan Christopher Chandra dan Ronnie Resdianto Masman (2020) Pengaruh Kompensasi dan Lingkungan Kerja terhadap Kinerja Karyawan Pada PT Klasik Distribusi Indonesia. Program Studi Manajemen Fakultas Ekonomi dan Bisnis Universitas Tarumanagara, Jakarta

Milkovich, G.T., Newman, J.M. \& Gerhart. B. (2014). Compensation. McGraw- Hill/Irwin, New York, USA

Rahadian Mohamad dan M. Tony Nawawi (2020) Pengaruh Organizational Learning, 
Organizational Commitment dan Job Satisfaction Terhadap Employee Performance di Jakarta. Program Studi S1 Manajemen Fakultas Ekonomi \& Bisnis Universitas Tarumanagara

Robbins, Stephen P. dan Coulter, Mary. 2011. Management. Pearson Education

Sanusi, A. (2011). Metodologi Penelitian Bisnis. Jakarta: Penerbit Salemba Empat.

Sekaran, U., \& Bougie, R. (2016). Research Methods for Business. Ed 7th. United Kingdom: Wiley.

Sugiyono. 2014. Metode Penelitian Pendidikan Kuantitatif dan Kualitatif dan R\&D. Bandung: CV Alfabeta.

Winner Clinton Purba dan Sri Langgeng Ratnasari (2018) Pengaruh Konflik Kerja, Stres Kerja dan Beban Kerja Terhadap Kinerja Karyawan PT. Mutiara Hutama Sukses, Manajemen, Universitas Riau Kepulauan. 